\title{
Components of Trust Influencing eGovernment Adoption in Germany
}

\author{
Cigdem Akkaya, Manuela Obermeier, Petra Wolf, and Helmut Krcmar \\ Technische Universität München, Chair for Information Systems I17, Boltzmannstr. 3, \\ 85748 Garching bei München, Germany \\ \{cigdem.akkaya, manuela.obermeier, petra.wolf, krcmar\} @in.tum.de
}

\begin{abstract}
User acceptance plays a pivotal role in success of all IS projects. Yet, most of the e-government endeavors worldwide have fallen short of their potential. Online transactions with public administrations are plagued with concerns of data protection and privacy resulting in reluctance to engage in egovernment. Although trust is confirmed to be an effective instrument for dealing with the anxiety of the faceless transactions, the majority of trust studies have been conducted in the context of e-commerce. Until now, relatively little research has focused on the role of trust influencing willingness of citizens to use e-government services. Based on a nationwide representative survey, our study contributes to prior literature by delivering the empirically-validated components of trust influencing the adoption of e-government in Germany. Enhanced with a research model of trust, this paper promotes a better understanding of the factors that halt or slow down e-government adoption in the German household.
\end{abstract}

Keywords: Trust, e-government, adoption, household, Germany.

\section{Introduction}

Lack of user acceptance is a significant impediment to the success of new technologies [1] which makes user acceptance the pivotal factor in determining the success or failure of any IS project [2]. Research about why users accept or reject information systems and factors to increase adoption has long been a popular topic in adoption of online services [3].

Electronic government is being increasingly recognized as a key facilitator for transforming public governance. Despite huge investments, e-government initiatives continue to lag far behind their expected potentials [4]. Most internet users are still reluctant to use online methods to interact with public authorities. It is remarkable to see that people participate in social networking sites, use e-commerce applications, perform their banking transactions online but hesitate to use internet to communicate with public authorities. In Germany, 72 percent of the population use internet [5]. The number of Facebook has nearly doubled only in the last nine months [6]. Last year, 75 percent of the German internet users purchased goods and services online, 49 percent used online banking, but only 39 percent downloaded forms of public authorities [7]. Citizens consider data protection and security as the most important issues in online 
banking however more than four out of every five people continue using it [8]. Considering the economical crises and worldwide data scandals, it is a notable result.

Skepticism, however, increases when government is the service provider. Particularly, citizens tend to suspect that government watches everything and gathers data about citizens through various channels [9]. Citizens do not exactly know how the collected data is used by the public authorities and consequently do not trust government. Moreover, due to the inherent nature of online transactions, citizens experience some level of risk and uncertainty. Various data scandals and harsh critics of nationwide projects involving transfer of sensitive personal data intensify concerns of citizens towards online public services. In these uncertain situations, enhancing trust becomes a crucial strategy for dealing with the risk and uncertainty of the transactions with the public authorities. Given the increasing prevalence of trust in egovernment research, building trust of citizens in e-government has recognized as the top research priority in Europe [10].

Previously, trust in e-government services was accepted as a single construct. With the increasing amount of trust research in this context, the authors have started distinguishing among the components of trust. We also believe that trust is a very broad concept with various dimensions in e-government research. Thus, it would be an oversimplification to observe trust as a single construct. Besides the concerns of technology, privacy concerns point out to the existence of trust to government. Recognizing the importance of trust as an underlying source of motivation for egovernment usage [11], the research questions for this paper are targeted to understand the particular role of trust in e-government adoption: What are the trustrelated barriers impeding the adoption of online public services in the German household? Which specific components and sub-components of trust can be identified in this context?

As the national culture and trust are proven to be closely related [12-14], many authors analyze the role of trust a specific national culture $[11,15]$ or compare them in cross-cultural studies [16]. The need for a specific empirical study focusing on the role of trust in e-government research of Germany was pointed out recently [17]. Hence, the focus of our paper is to provide insights into the components of trust that are valid for the national culture of Germany. In particular, our research is important for practitioners, policy makers and academics as it includes a nationwide representative survey reflecting the current perceptions of the German households.

The document is organized as follows. The next section reviews the existing trust literature in the context of e-government adoption, particularly focusing on the components of trust. Having argued the necessity of trust for the success of the ongoing and future projects, the following three sections focus on a recent, nationwide representative survey about the awareness and adoption of e-government in the German household. Section three describes the method applied to carry out the research and section four summarizes the main findings. This is followed by a discussion in the subsequent section, which also includes implications, limitations and future directions of this research. We conclude by summarizing the key findings arising from our research. 


\section{Literature Review}

Trust is a ubiquitous feature that is essential to all types of transactions [18]. Particularly in the context of attracting new customers, trust is found to be "an extremely important economic factor" [19]. It is accepted as a main antecedent influencing customer loyalty in e-service context [20]. Thereby, trust is an important driving force to influence the initial and continued use of an e-service. Researchers have long acknowledged that the need for trust arises only in the presence of risk [21]. Risk causes uncertainty and insecurities, whereas trust is an effective coping mechanism and "willingness to take risk" [22] by changing its perception.

E-government services are by nature online services which require involvement of technology, citizens and governmental organizations. There exists an extensive amount of literature about the role of trust, its antecedents and implications influencing the online shopping behavior [23-25]. However, we see that research in the context of e-government has recently started to emerge. Although some studies have underlined the importance of trust for the e-government adoption previously [16, 26], most of the empirical work have been conducted in the last couple of years. Most studies have mentioned trust as a significant predictor of usage among others [27-29]. Recognizing the importance of the issue in the context of e-government, studies have emerged focusing mainly on trust as an acceptance factor in e-government [30].

Previously, trust in e-government services was accepted as a single construct [16]. With the increasing amount of trust research in this context, the authors have started conceptualizing trust as a combination of different components such as disposition to trust, trust in technology and trust in government. The literature reveals no consensus on the categorization of sub-factors as dimensions, constructs, components or determinants of trust. The study of Carter and Belanger [28] was among the first research in the context of e-government that conceptualizes trust in two different components: (1) trust of government and (2) trust of internet. Similarly Srivastava and Teo [31] discussed the component of trust on government and extended the trust of internet to a more broader term of trust on technology. Following these publications, the dimensions of trust in government and trust in technology have been subject to other researches [32]. There has not been a consistency in terms of trust components. Some studies have analyzed trust as a single component: trust in e-government services [33] or trust in government [34, 35]. A few authors have used a combination of component and sub-component in the same research: trust in e-government services and trust in government [36]. The study of Belanger and Carter [37] was a milestone which analyzed purely the role of trust and risk in e-government adoption, rather than observing trust as one of the several antecedents among the others. In their research, the authors have expanded the number of trust dimensions compared to their previous work [28]: disposition to trust, trust of the internet, trust of the government and added the factor perceived risk, which is a commonly included construct in online trust research.

There has been no consensus on the components of trust in e-government research. Colesca [38] analyzed trust in technology and propensity to trust among the factors of increasing trust on e-government. Alsaghiar et al. [39] used the components of 
disposition to trust and used institution-based trust in the e-government context. Institution-based trust was previously used in the context of online shopping [40] referring to the belief that needed structural conditions are present to enhance the probability of achieving a successful outcome. Some researchers analyzed components of trust in other categorizations. Liet et al. [41] discussed the concept of trusting bases to the context of e-government (personality, cognitive, calculative, institutional), which have been previously applied in trust research for the context of online shopping [42]. Recently, Dashti et. al. [43] introduced the concept of felt trust influencing trust in e-government. Despite the different categorizations and naming conventions, the recognition of the need to divide trust into various components rather than observing it as a single antecedent is a proof of advancements in the trust research in e-government.

\section{Methodology}

The findings presented here are taken from the nationwide e-government survey, which has been conducted together with TNS Infratest. The study was carried out between $7^{\text {th }}$ and $20^{\text {th }}$ of June 2010. Interviews were conducted online with a nationwide representative sample of 1,002 internet users in private households by an online panel weighted by central features like gender, age and formal education. The study focuses on the e-government usage for the internet users of private households in Germany. Participants answered questions about the importance of e-government services, barriers to adoption of e-government, concerns of data security and privacy. The final sample comprised $n=1,002$ adults (46\% female and $54 \%$ male) who are older than 18 years. Thirty-two percent $(32 \%)$ are between the ages 18 to 34 years, forty-four percent $(44 \%)$ are in the 35-54 age group and twenty-four percent $(24 \%)$ of the sample are over the age 55. The importance of factors for using e-government services was measured on a five-point Likert-scale (1=least important to $5=$ crucial) and the barriers to adoption of e-government services were measured on a four-point Likert-scale ( $1=$ strongly disagree to $4=$ strongly agree). The numbers given in the figure and tables are calculated using the top two-box scores.

\section{Results}

The study has revealed valuable insights about the concerns of citizens impeding adoption of e-government in Germany. By taking part in this nationwide survey, we aimed to gain insights to specific role of trust and its components in the adoption of egovernment in Germany. The survey included other aspects such as the familiarity and satisfaction with the e-government services as well as the future potential usage of mobile services (m-government) which goes beyond our research. In order to stay focused, we only include the questions that are directly relevant for our research.

The first question investigated the importance of the factors influencing egovernment usage. As shown in Figure 1 below, various factors affect the use of 
online public services. Among them, data protection/privacy has strongest impact on the citizen engagement in e-government. This is closely related to trust in government since the government is responsible from protection of the data transmitted. However, the respondents might have also referred to the security concerns such as the third party access. Such a concern would point out to concerns related to the medium of transaction, which would be categorized under trust in technology. This issue will be analyzed further in another question.

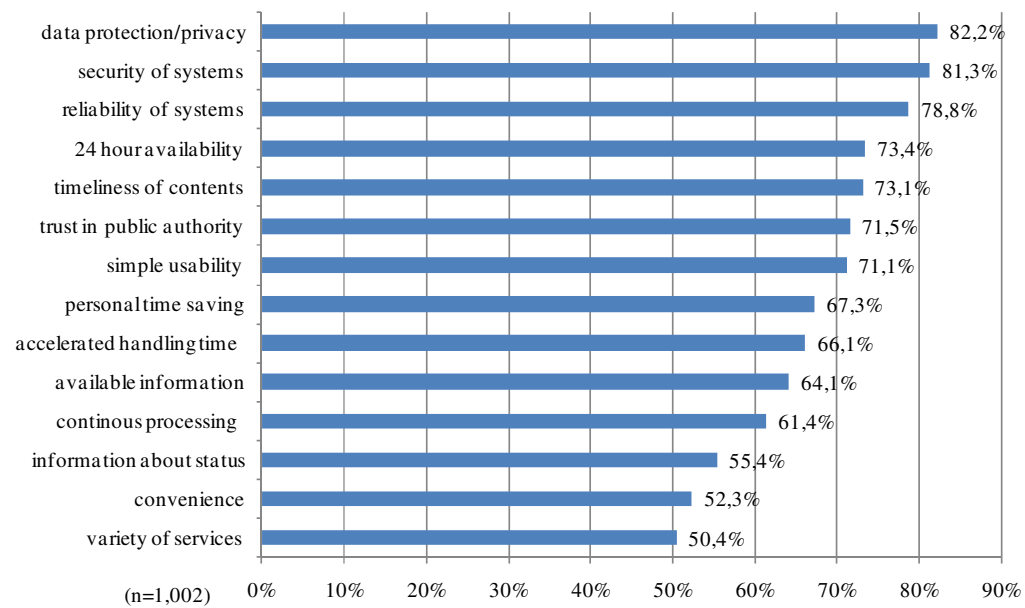

Fig. 1. Factors influencing use of e-government services [based on 5]

The next two important factors influencing use of e-government services were given as security and reliability of systems. These issues are also closely related to trust in technology, including the underlying infrastructure and transmitting medium. Moreover, the sixth factor trust in respective public authority is a clear statement referring to trust in government. For more than seventy percent of citizens, trust in the public authority was stated as an important requirement for engaging in online public services.

In the second question, the specific barriers to use of e-government services were questioned. As summarized below in Table 1, lack of data protection/privacy (33.8\%) and lack of trust in public authority (26.5\%) were among the barriers to usage of egovernment services. These findings intensify the importance of trust in technology and trust in government respectively. The survey revealed other important barriers including impersonability of the services, lack of consistency, unclear structure, complicated services, lack of help and assistance. While it may be possible to discuss the indirect influence of these factors on trust - especially for the factor of lack of help - these aspects are not considered directly relevant to the issue of trust or to its components. Instead, they signify the low maturity level of e-government services in Germany [4]. 
Table 1. Barriers to use of e-government services [based on 5]

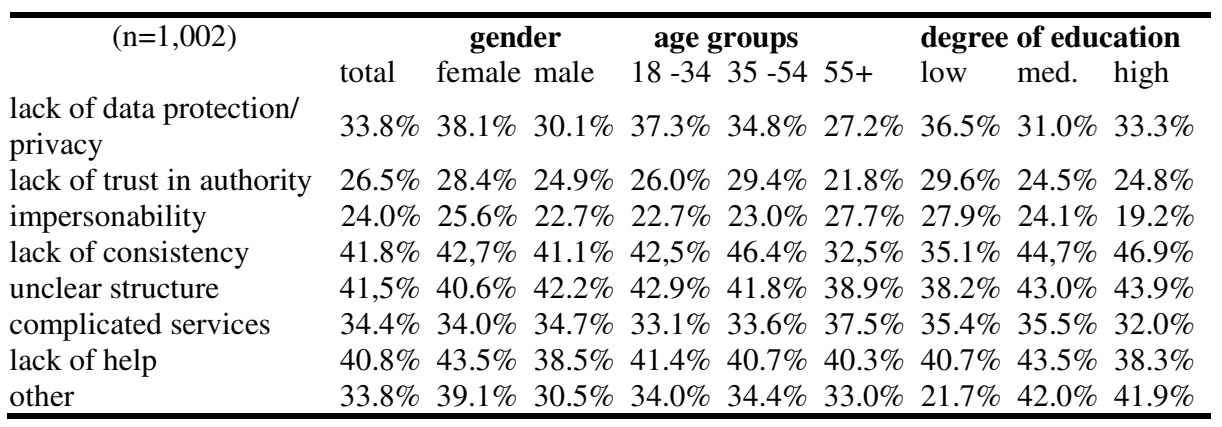

Due to our special research interest, respondents who have specified data protection/privacy as a barrier to adoption were asked to specify their concerns further in the third question $(n=337)$. Our intention was to receive insights about the specific concerns underlying data protection/privacy, which was stated in the first question. The results of the third question delivered valuable information regarding to underlying risk perceptions, which lead to trust components. The results are summarized in Table 2 below.

Table 2. Concerns regarding data protection/privacy [based on 5]

\begin{tabular}{|c|c|c|c|c|c|c|c|c|c|}
\hline \multirow[t]{2}{*}{$(n=337)$} & \multirow[b]{2}{*}{ total } & \multicolumn{2}{|c|}{ gender } & \multicolumn{2}{|c|}{ age groups } & & \multicolumn{3}{|c|}{ degree of education } \\
\hline & & female & male & $18-34$ & $35-54$ & $55+$ & low & med. & high \\
\hline $\begin{array}{l}\text { inadequate security } \\
\text { of transferred data }\end{array}$ & $70.5 \%$ & $68.5 \%$ & $72.8 \%$ & $75.0 \%$ & $69.4 \%$ & $64.8 \%$ & $72.7 \%$ & $68.8 \%$ & $69.4 \%$ \\
\hline $\begin{array}{l}\text { fear of "transparent } \\
\text { citizen" }\end{array}$ & $60.8 \%$ & $61.0 \%$ & $60.5 \%$ & $52.8 \%$ & $65.3 \%$ & $65.1 \%$ & $55.7 \%$ & $62.9 \%$ & $65.4 \%$ \\
\hline $\begin{array}{l}\text { confidential handling } \\
\text { of sensitive data }\end{array}$ & $57.9 \%$ & $55.7 \%$ & $60.3 \%$ & $50.2 \%$ & $61.8 \%$ & $63.2 \%$ & $55.7 \%$ & $60.8 \%$ & $58.1 \%$ \\
\hline none of the above & $6.7 \%$ & $4.4 \%$ & $9.2 \%$ & $5.9 \%$ & $6.8 \%$ & $7.9 \%$ & $5.3 \%$ & $5.2 \%$ & $10.0 \%$ \\
\hline do not know & $2.2 \%$ & $3.2 \%$ & $1.2 \%$ & $2.8 \%$ & $1.6 \%$ & $2.4 \%$ & $3.6 \%$ & $0.8 \%$ & $1.7 \%$ \\
\hline
\end{tabular}

We see that respondents referred not only to government related aspects. They had also technology related concerns under the data protection/privacy. The respondents state mainly three specific concerns regarding data protection/privacy. The first one is the inadequate security of transferred data, which can be categorized under trust in technology. The other two important factors were about protection of personal private sphere which necessitate trust in government as an important precondition.

With this survey, we have questioned the factors influencing the use of e-government services, with a specific focus on barriers and concerns. It is remarkable to see most important aspects are related to a competent of trust. This validates the increasing importance of the issue of trust in e-government research. The results are generalizable to the entire population in Germany, which are summarized in the next section. 


\section{Discussion}

Findings of the survey indicate that concerns about data protection, privacy, security and lack of trust in respective public authority are important barriers to use of egovernment services in Germany. One out of every three citizens states concerns of data protection/privacy as a barrier to use of e-government. Among them, more than seventy percent $(70 \%)$ have concerns regarding the security of transmission, sixtyone percent $(61 \%)$ report the fear of becoming a transparent citizen and fifty-eight percent $(58 \%)$ state concerns about confidential handling of sensitive data.

The results of study reveal that perceived risk in the case of online public services is quite high in Germany. This result confirms the belief about the German nation which is "widely considered to be risk-averse" [44]. We suggest the usage of trust as an effective instrument to deal with the perceived risk and uncertainty. Potential users should be assured that the data transmission is secure and the underlying infrastructure is reliable. Moreover, they must be ensured that governmental agencies will respect to their privacy and handle their sensitive data confidentially. They need to be assured that e-government services are offered to provide benefits rather than monitoring the society. It is not an easy goal and will likely to be quite tedious to achieve. Even one data scandal in this context can damage public trust severely. Citizens can change companies as service providers but government is and will be the one and only provider of e-government. Thus, building trust of citizens is essential for increasing the adoption and continued usage of online public services.

Having underlined the importance of trust, this study provides also valuable insights for future empirical research. Based on the survey, we propose the following research model.

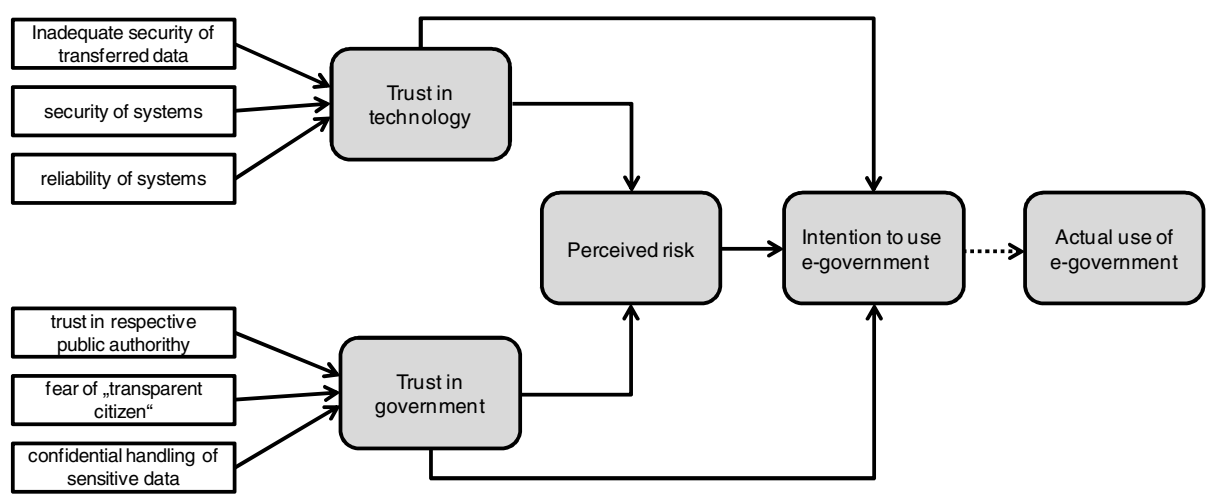

Fig. 2. Proposed research model

This research model includes the two main components of trust and their further sub-components. Our research model draws its theoretical foundation from the basis conceptual framework underlying models of well-known theories TAM [45], TRA [46] and TPB [47] explaining individual acceptance of information technology. As discussed by Venkatesh et al. [48], well-known adoption theories have the same basis conceptual framework: individual beliefs to using IS - intentions to use IS - actual use 
of IS. According to this theoretical basis, an individual's behavior is predicted by his or her intention to perform this behavior. Intention to perform the behavior is further influenced by the underlying beliefs. The actual behavior being the use of egovernment services, our model should deliver the influence of trusting beliefs and perceived risk on the intention to use e-government services, which is found to be an accurate predictor of actual behavior in many IS and human behavior studies [49].

Based on the survey, constructs of the proposed research model are summarized below. As the third question revealed specific concerns underlying the factor of data protection/privacy, these factors were included in the model, rather than the data protection/privacy as a single construct, which has reflections on both in trust in technology and trust in government.

- Trust in technology: The results of the survey shows that citizens perceive risk in the areas of system robustness and security of the transferred data. These issues can be summarized under the aspect of trust in technology, which is the first factor of trust.

- Trust in government: Trust in public authority has been stated explicitly and constitutes the second factor of trust. Fear of becoming a "transparent citizen" and concerns regarding confidential handling of sensitive data are aspects regarding privacy by the government. Thus, these two sub-components of trust are categorized under trust in government.

- Perceived risk: Although this item was not specifically stated, respondents stated several concerns about using the online public services. Moreover, trust is closely related to risk in question and the need for it arises only in the presence of risk [21, $50,51]$. In prior research, an online user's perceived risk has been found to influence his or her online decision [52]. Therefore, we believe any research model of trust in e-government should also include the construct of perceived risk.

Although this paper provides valuable insights into the factors of trust affecting citizen decision making in Germany, it has certain limitations. First, survey questions were not developed based on a theoretical framework. This may have reduced the number of synthesized components of trust such as the frequently discussed disposition to trust - which is defined as one's general propensity to trust others [42] - and trust in personal skills and knowledge regarding the usage of online services. Second, due to our specific focus on the national culture of Germany, foreigners living in Germany were not included who are also potential users of e-government services in Germany. We suggest future research to broaden the model with trust constructs based on previous studies in literature and empirically validate them. Another interesting area for future research is the comparison of the differences of intention to use among various age groups. We expect that the young generation is more comfortable in providing personal data about themselves due to their common usage of online social platforms. On the other hand, the confidential handling of the collected data may be among the main concerns of the relatively older generations due to their conservation. Future research should also consider integrating dimensions of national culture [53] as a construct in order to enable cross-cultural analysis.

Despite its limitations, however, this paper yields valuable insights about the role and components of trust affecting the adoption of online public services in Germany. It suggests a trust-based research model for future researchers in order to question the 
role of trust in the adoption of e-government. Besides the discussed theoretical implications, the findings of this research have also practical implications for practitioners and policy makers. From a practical standpoint, the results highlight the importance of trust for dealing with the risk perceived of using online public services. Hence, any effort to increase adoption of e-government in Germany should ensure various trust constructs stated in this study. Citizens have to be convinced that security and privacy mechanisms are in place. Considering the maturity of trust research in e-commerce context, the trust-building mechanisms of well-known, trusted online companies and Web 2.0 applications should be analyzed for adaptability in the context of e-government.

\section{Conclusion}

The adoption of e-government initiatives in the household context depends on citizens' willingness to adopt them. However, the expected potential of e-government services has not been exploited in many countries. Citizens worldwide are concerned about the risks of online transactions and increasingly aware about their privacy. News in global media about cybercrime and invasion of privacy increases the sensitivity of people, which impedes the nationwide acceptance of e-government projects. They have considerable reluctance to use e-government services compared to making transactions with companies and participating in social media platforms and weblogs.

Despite its importance, the role of trust influencing the adoption and continued use of e-government is still relatively under-researched. We argue that the decision making of citizens towards online public services can be better understood with a comprehensive analysis of the issue of trust. If the citizens perceive public authorities as "data collectors" and hence do not trust them, the adoption of e-government will remain a lasting problem. Our research sheds light on explaining and predicting the process of egovernment adoption by citizens in Germany. The suggested research model includes two empirically validated components of trust - trust in government, trust in technology - and six sub-components influencing use of online public services. Integration of new constructs based on prior literature could support obtaining a more complete picture on the aspect of trust. For instance, disposition to trust, trust in personal skills and knowledge are likely to be relevant in the context of e-government. Researchers aiming cross-cultural studies should add relevant cultural constructs. In order to derive conclusions about the citizens of Germany, however, the extended model needs to be empirically validated in a nationwide representative study.

Besides its theoretical implications, this research has important practical implications. Since, one out of every three citizens considers data protection as a barrier to use of e-government; the government in Germany needs to closely examine the approaches to build trust of its citizens to decrease the perceived risk of citizens. Our research reveals that citizens have concerns regarding both the technology and the public authorities. Trust-building mechanisms of online banking, e-commerce and Web 2.0 applications such as third party seals, structural assurances and effective communication should be analyzed for adaptability to e-government. 
Acknowledgments. We would like to thank to TNS Infratest GmbH for letting us to participate in the conduct of the survey and to International Data Group (IDG) Business Media GmbH for the kind permission to publish it.

\section{References}

1. Gould, J.D., Boies, S.J., Lewis, C.: Making Usable, Useful, Productivity-Enhancing Computer Applications. Communications of the ACM (CACM) 34, 74-85 (1991)

2. Davis, F.D.: User acceptance of information technology: system characteristics, user perceptions and behavioral impacts. International Journal of Man-Machine Studies 38, 475-487 (1993)

3. Dwivedi, Y.K., Williams, M.D., Lal, B., Schwarz, A.: Profiling Adoption, Acceptance and Diffusion Research in the Information Systems Discipline. In: 16th European Conference on Information Systems (ECIS), pp. 1204-1215 (2008)

4. United Nations: United Nations E-Government Survey (2010)

5. TNS Infratest: (N)ONLINER Atlas eGovernment - Monitor (2010)

6. http://facebookmarketing.de

7. Statistisches Bundesamt Deutschland: Private Hauhalte in der Informationsgesellschaft Nutzung von Informations- und Kommunikationstechnologie (2009)

8. TNS Infratest: (N)ONLINER Atlas 2010, Sonderstudie Online-Banking (2010)

9. Belanger, F., Hiller, J.S.: A framework for e-government: privacy implication. Business Process Management Journal 12, 48-60 (2006)

10. Wimmer, M.A., Codagnone, C.: Roadmapping eGovernment Research: Visions and Measures towards Innovative Governments in 2020 (2007)

11. Carter, L., Weerakkody, V.: E-government adoption: A cultural comparison. Information Systems Frontiers 10, 473-482 (2008)

12. Jarvenpaa, S., Tractinsky, N., Vitale, M.: Consumer Trust in an Internet Store. The International Journal of Information Technology and Management 1, 45-71 (2000)

13. Doney, P.M., Cannon, J.P., Mullen, M.R.: Understanding the influence of national culture on the development of trust. Academy of Management Review 23, 601-620 (1998)

14. Fukuyama, F.: Trust: The Sociel Virtues and the Creation of Prosperity. Free Press, New York (1995)

15. Srivastava, S.C., Teo, T.S.H.: Citizen Trust Development for E-Government Adoption and Usage: Insights from Yound Adults in Singapore. Communications of the Association for Information Systems 25, 359-378 (2009)

16. Warkentin, M., Gefen, D., Pavlou, P.A., Rose, G.M.: Encouraging Citizen Adoption of eGovernment by Building Trust. Electronic Markets 12, 157-162 (2002)

17. Akkaya, C., Wolf, P., Krcmar, H.: The Role of Trust in E-Government Adoption: A Literature Review. In: Proceedings of the 16th Americas Conference on Information Systems (AMCIS), p. 297 (2010)

18. Arrow, K.J.: The limits of organization. Norton, New York (1974)

19. Bhide, A., Stevenson, H.: Trust, uncertainty, and profit. Journal of Socio-Economics 21, 191-208 (1992)

20. Luarn, P., Lin, H.-H.: A Customer Loyalty Model for e-Service Context. Journal of Electronic Commerce Research 4, 156-167 (2003)

21. Adams, J.: Risk. UCL Press, London (1995)

22. Mayer, R.C., Davis, J.H., Shoorman, F.D.: An Integrative Model of Organizational Trust. Academy of Management Review 20, 709-734 (1995) 
23. Kim, D.J., Ferrin, D.L., Rao, H.R.: A trust-based consumer decision-making model in electronic commerce: The role of trust, perceived risk, and their antecedents. Decision Support Systems 44, 544-564 (2008)

24. Lee, M.K.O., Turban, E.: A Trust Model for Consumer Internet Shopping. International Journal of Electronic Commerce 6, 75 (2001)

25. Shankar, V., Urban, G.L., Sultan, F.: Online trust: a stakeholder perspective, concepts, implications, and future directions. The Journal of Strategic Information Systems 11, 325 344 (2002)

26. Wang, Y.-S.: The adoption of electronic tax filing systems: an empirical study. Government Information Quarterly 20, 333-352 (2003)

27. Gilbert, D., Balestrini, P., Littleboy, D.: Barriers and benefits in the adoption of egovernment. International Journal of Public Sector Management 17, 286-301 (2004)

28. Carter, L., Belanger, F.: The utilization of e-government services: citizen trust, innovation and acceptance factors. Information Systems Journal 15, 5-25 (2005)

29. Hung, S.-Y., Chang, C.-M., Yu, T.-J.: Determinants of user acceptance of the eGovernment services: The case of online tax filing and payment system. Government Information Quarterly 23, 97-122 (2006)

30. Gefen, D., Rose, G.M., Warkentin, M., Pavlou, P.A.: Cultural Diversity and Trust in IT Adoption: A Comparison of Potential e-Voters in the USA and South Africa. Journal of Global Information Management 13, 54-78 (2005)

31. Srivastava, S.C., Teo, T.S.H.: Citizen Trust Development for E-Government Adoption: Case of Singapore. In: Proceedings of the Ninth Pacific Asia Conference on Information Systems, PACIS 2005 (2005)

32. Teo, T.S.H., Srivastava, S.C., Jiang, L.: Trust and Electronic Government Success: An Empirical Study. Journal of Management Information Systems 25, 99-131 (2008)

33. Sang, S., Lee, J.-D., Lee, J.: E-government adoption in ASEAN: the case of Cambodia. Internet Research 19, 517-534 (2009)

34. Welch, E.W., Hinnant, C.C., Moon, M.J.: Linking Citizen Satisfaction with E-Government and Trust in Government. Journal of Public Administration Research and Theory 15, 371391 (2004)

35. Shalini, R.T.: Are Mauritians ready for e-Government services? Government Information Quarterly 26, 536-539 (2009)

36. Horst, M., Kuttschreuter, M., Gutteling, J.M.: Perceived usefulness, personal experiences, risk perception and trust as determinants of adoption of e-government services in The Netherlands. Computers in Human Behavior 23, 1838-1852 (2007)

37. Belanger, F., Carter, L.: Trust and risk in e-government adoption. Journal of Strategic Information Systems 17, 165-176 (2008)

38. Colesca, S.E.: Increasing E-Trust: A Solution To Minimize Risk In E-Government Adoption. Journal of Applied Quantitative Methods 4, 31-44 (2009)

39. Alsaghier, H., Ford, M., Nguyen, A., Hexel, R.: Conceptualising Citizen's Trust in eGovernment: Application of Q Methodology. Electronic Journal of e-Government 7, 295 310 (2009)

40. McKnight, D.H., Choudhury, V., Kacmar, C.: Developing and Validating Trust Measures for e-Commerce: An Integrative Typology. Information Systems Research 13, 334-359 (2002)

41. Li, X., Hess, T.J., Valacich, J.S.: Why do we trust new technology? A study of initial trust formation with organizational information systems. Journal of Strategic Information Systems 17, 39-71 (2008) 
42. Gefen, D., Karahanna, E., Straub, D.W.: Trust and TAM in Online Shopping: An Integrated Model. MIS Quarterly 27, 51-90 (2003)

43. Dashti, A., Benbasat, I., Burton-Jones, A.: Developing trust reciprocity in electronic government: the role of felt trust. In: European and Mediterranean Conference on Information Systems (2009)

44. The Lauder Institute: Lauder Global Business Insight Report 2009: First-hand perspectives on the global economy (2009)

45. Davis, F.D.: Perceived Usefulness, Perceived Ease of Use, and User Acceptance of Information Technology. MIS Quarterly 13, 319-340 (1989)

46. Fishbein, M., Ajzen, I.: Attitude, Intention and Behavior: An Introduction to Theory and Research. Addison-Wesley, Reading (1975)

47. Ajzen, I.: The Theory of Planned Behavior. Organizational Behaviour and Human Decision Processes 50, 179-211 (1991)

48. Venkatesh, V., Morris, M.G., Davis, G.B., Davis, F.D.: User Acceptance of Information Technology: Toward a unified view. MIS Quarterly 27, 425-478 (2003)

49. Legris, P., Ingham, J., Collerette, P.: Why do people use information technology? A critical review of the technology acceptance model. Information \& Management 40, 191 (2003)

50. Luhmann, N.: Vertrauen: Ein Mechanismus der Reduktion sozialer Komplexität. Enke, Stuttgart (1989)

51. Coleman, J.S.: Foundations of social theory. Belknap Press, Cambridge (1990)

52. Antony, S., Lin, Z., Xu, B.: Determinants of escrow service adoption in consumer-toconsumer online auction market: an experimental study. Decision Support Systems 42, 1889-1900 (2006)

53. Hofstede, G.: Culture's Consequences:International Differences in Work-Related Values. Sage, London (1980) 